\title{
O SENTIDO COMO MÁQUiNA dE GUERRA CONTRA A NATURALIZAÇÃO DO PSÍQUICO
}

Rosane Zétola Lustoza ${ }^{\star}$

\begin{abstract}
Resumo
Este trabalho discute como a adoção do conceito de sentido permitiu a Lacan renovar a condução da praxis analítica. Recorrendo à obra de Lacan e comentadores, o conceito de sentido será investigado em seu duplo aspecto, tanto crítico - como forma de combate às propostas de naturalização do psíquico - quanto propositivo - como responsável pelo estabelecimento da intersubjetividade como dimensão fundamental da experiência clínica. Embora admitindo que Lacan posteriormente tenha subordinado o sentido à estrutura, abandonando a noção de intersubjetividade, o artigo examina o legado da teoria do sentido para a psicanálise. Sua principal contribuição foi o combate à naturalização do sujeito.
\end{abstract}

Palavras-chave: Psicanálise; Lacan; sentido; causalidade; naturalização.

\section{The Meaning AS A WAR MACHINE AGAINST THE}

\section{NATURALIZATION OF PSYCHISM}

\begin{abstract}
This study discuss how the concept of Meaning allowed Lacan to reconduct the analytical praxys. Appealing to works of Lacan and commentators, the concept of meaning will be investigated in its double aspect, the critic one - as means to fight the claims of naturalization of the psyche; and the postulated one - as responsible for the settlement of intersubjectivity as a fundamental dimension to capture the clinical experience. Although assuming that Lacan later abandoned intersubjectivity, the article examines the legacy of the theory of "Meaning" in psychoanalysis. Its main contribution would have been the fight against the naturalization of the subject
\end{abstract}

Keywords: Psychoanalysis; Lacan; meaning; causality; naturalization.

\footnotetext{
^ Professora Adjunta da Universidade Estadual de Londrina (UEL). Doutora em Teoria Psicanalítica pela Universidade Federal do Rio de Janeiro. Endereço: Rodovia Celso Garcia Cid . Pr 445 Kmb580. Cep: 86.055-900- Londrina- PR.

E-mail:rosanelustoza@yahoo.com.br
} 


\section{A noÇÃo de SEnTIdo COMo MÁQuina de GUERRa CONTRA A naturalizaÇão DO PSIQUISMO}

Julgando que o movimento psicanalítico havia se extraviado do verdadeiro sentido da experiência inaugurada por Freud, Lacan empreendeu um esforço de releitura do seu texto. Se partirmos da distinção, feita por Bachelard, (1996) entre história da ciência e epistemologia, ${ }^{1}$ a empreitada de Lacan não poderia ser situada apenas como uma tentativa de historiar o pensamento de Freud, pois um historiador se limitaria a tratar as ideias freudianas como se fossem fatos, quanto aos quais não caberia julgar o valor de verdade. Ora, foi desde o início algo muito diferente o que animou a pesquisa de Lacan: procurar, não o que Freud verdadeiramente disse, mas sim o que Freud teria dito de verdadeiro. A teorização de Lacan se insere num esforço epistemológico, em que se busca extrair qual verdade do psiquismo teria sido inaugurada pela experiência analítica.

Evidentemente, houve um trabalho de extração dessa verdade, a qual não se apresentou de forma definitiva. Inicialmente, Lacan acreditou ser a psicanálise portadora de uma verdade que a colocava em perfeita sintonia com o movimento de ideias, inaugurado por W. Dilthey (1986[1883]), segundo o qual as condutas humanas, por não estarem integralmente submetidas ao determinismo da natureza, constituiriam um domínio separado da esfera natural, a saber, o domínio do sentido. Embora esta perspectiva não recusasse a existência de um denominador comum ligando o homem aos outros seres vivos, pretendia valorizar justamente aquilo que, no homem, escapava ao determinismo da natureza, ou seja, sua liberdade e sua capacidade de conferir sentido ao que acontece. Como haveria de fato na obra de Freud uma dimensão interpretativa, que considera os atos psíquicos como portadores de um sentido latente, diversos autores situaram a psicanálise como uma ciência que decifra a mensagem oculta dos sonhos, atos falhos e sintomas (MONZANI,1989). Ao empreender sua releitura da obra freudiana, Lacan adere inicialmente a essa posição:

$\mathrm{O}$ gesto inaugural de Lacan consiste em esposar incondicionalmente a hermenêutica: desde sua tese de doutorado de 1933, e especialmente no Discurso de Roma, ele se opõe ao determinismo em nome da psicanálise como pesquisa hermenêutica: "Toda experiência analítica é uma experiência de significação". É aí que se origina o grande tema lacaniano do futuro anterior da simbolização: um fato não vale como fato bruto, mas somente como sempre-já historizado" (ZIZEK, 1999, p. 125).

O objetivo do presente artigo é isolar em que aspectos o conceito de sentido possibilitou a Lacan renovar a questão da condução da práxis psicanalítica, particularmente no que concerne à recusa da assimilação da psicanálise às ciências da natureza, tal como era pensada e praticada pelos autores denominados pós-freudianos. A tese é a de que, mesmo que posteriormente tenha abandonado os pilares fundamentais da teoria do sentido, Lacan conservou terminantemente 
desta noção a função crítica, concedendo-lhe o importante papel de máquina de guerra contra a naturalização do psiquismo. Ou seja, por mais que a teoria do sentido tenha sido posteriormente descartada por Lacan em favor de outras posições, "o fato de que ele tenha se desviado da hermenêutica não significa nenhuma regressão ao naturalismo" (ZIZEK, 1999, p. 126), permanecendo válida esta recusa inicial em considerar a psicanálise como ciência natural.

A pertinência de uma tal investigação justifica-se mais fortemente, já que presenciamos hoje em dia um revigoramento das posições naturalistas. De fato, uma série de avanços tecnológicos trouxe novas perspectivas para o estudo do cérebro, como as técnicas de produção de imagens (tomografia, ressonância magnética etc.), mapeamento da atividade elétrica cerebral etc. Além disso o avanço da psicofarmacologia proporcionou o lançamento de medicamentos psicotrópicos muito mais eficazes e variados. Tais fatores contribuíram para a ascensão de uma psiquiatria biológica, cujo pressuposto central é de que o cérebro é um órgão da mente (AGUIAR, 2004). Diante desses progressos, a técnica freudiana parece para alguns obsoleta, por esperar que a cura do sofrimento psíquico venha da palavra. Em face deste novo boom naturalista, a noção de sentido ainda é capaz de servir à psicanálise, ajudando-a a livrar-se de falsos problemas.

No entanto, embora tenha-se revelado útil pelo seu aspecto crítico, a noção de sentido acabou mostrando-se também problemática, obrigando Lacan a subordiná-la a outros conceitos. Primeiramente, a partir da adoção de um referencial estruturalista, o sentido torna-se efeito da combinatória significante, passando, portanto, a ocupar um papel secundário na teoria. Posteriormente, a própria noção de uma estrutura fechada, cujas leis de organização determinariam a formação do significado, será submetida à revisão. Em seu lugar, entra em cena agora justamente a ideia de algo na estrutura que escaparia a qualquer legalidade: o objeto a. Ainda que escape ao alcance do presente trabalho apresentar as razões de todas essas reformulações, não se pode contudo ignorá-las. Por isso, ao se extrair as conseqüências da adoção de uma teoria do sentido para a clínica psicanalítica, serão ressaltados os pontos que serão ulteriormente submetidos a um reexame crítico por parte de Lacan.

O trabalho analisará dois textos de Lacan: "Formulações sobre a causalidade psíquica" (1998[1946]) e "Função e campo da fala e da linguagem em psicanálise" (1998[1953]) Estes textos foram escolhidos pela seguinte razão: o primeiro por se colocar frontalmente contra a possibilidade de encontrar uma causalidade física do psiquismo, tal como pretendia o organicismo de Henri Ey (1950[1946]); o segundo por introduzir a retomada da experiência freudiana valorizando a questão da fala plena e da fala vazia. A investigação divide-se em duas etapas. A primeira parte do trabalho explicita como a adoção de uma teoria do sentido serviu como um embargo lógico a qualquer tentativa de encontrar uma determinação físico-orgânica do psíquico. Dessa maneira, ainda que grande parte das formulações de Função e campo não tenham resistido aos desenvolvimentos posteriores da obra lacaniana, a crítica ali empreendida contra os projetos de objetivação do 
psíquico não caducou jamais, já que, conforme será mostrado, a consequência lógica de tais projetos é a inviabilização de uma clínica do sujeito. Num segundo momento, será apresentado o impacto da teoria do sentido sobre a clínica.

\section{Parte I- As consequências da naturalização do Psíquico}

A atividade científica moderna caracteriza-se fundamentalmente pelo emprego do princípio do determinismo a fim de tornar inteligível a realidade física. Conforme ensina Robert Blanché (1975, p. 128), o conceito científico de "determinação" deve ser entendido no sentido "matemático" do termo: um dado problema encontra-se determinado quando admitir uma e apenas uma solução, indeterminado quando admitir várias soluções possíveis. Assim, na equação $x+1=7$ há um e somente um valor passível de ser assumido por x, portanto a equação é determinada para $\mathrm{x}$, ao passo que em $\mathrm{x}+\mathrm{y}=9$ pode-se admitir diversos valores para $\mathrm{x}$, conseqüentemente, a equação não é determinada para $\mathrm{x}$. Da mesma maneira, um problema de física é dito determinado quando seu enunciado admite uma e apenas uma solução. Por exemplo, se o estado presente de um sistema fechado permite calcular seu estado num instante passado ou futuro, dizemos que ele os determina. "A palavra "determina" tem aqui um sentido puramente lógico: certo número de variáveis determina uma outra variável se esta outra variável é uma função das primeiras" (RUSSELL, 1957, p. 215).

Em síntese, há determinismo quando é possível estabelecer uma relação de dependência necessária de uma variável y em relação a uma variável x, de tal maneira que para certo valor de $\mathrm{x}$, será possível um e somente um valor de $\mathrm{y}: \mathbf{y}=$ $\mathbf{f}(\mathbf{x})$. Quando dizemos que haveria uma ligação necessária entre as variáveis $\mathrm{x}$ e y, qual a noção de necessidade aqui em jogo? Quando afirmamos que para certo valor de $\mathrm{x}, \mathrm{y}$ assume necessariamente um determinado valor, significa que uma vez dado $\mathrm{x}$, y se dará fatalmente, obrigatoriamente, inexoravelmente, que ele não poderá deixar de ocorrer.

Uma vez que as ciências da natureza avançaram cada vez mais em sua tarefa de tornar inteligível o mundo físico empregando o princípio do determinismo, pôde-se indagar se não seria possível repetir o sucesso desse empreendimento aplicando tal princípio a outro domínio, o do psíquico. Isto significaria considerar o psiquismo uma realidade que, embora diferente da realidade física graças a características específicas, seria, tanto quanto ela, submetida a leis naturais, e passível, portanto, de ser estudada por uma ciência experimental.

Desta premissa - o psiquismo encontra-se submetido ao determinismo da natureza - pode-se deduzir logicamente três importantes conseqüências.

1) Conforme foi dito, o determinismo pode-se exprimir sob a forma de uma lei funcional: uma vez em que fixado um certo valor da variável x, "seguese necessariamente" um e somente um valor da variável $\mathrm{y}$. Transportando este raciocínio para o campo das condutas humanas, torna-se possível afirmar que, uma vez presente certo fato $\boldsymbol{x}$, seja ele físico ou orgânico, deve "seguir-se necessariamente" uma determinada conduta $\boldsymbol{y}$. Uma vez presente um determinado 
estado psico-fisiológico, o sujeito não poderia ter agido, pensado ou sentido de outra maneira. Se alguém se conduz de certo modo graças a um mecanismo que o constrangeu, que o obrigou a fazer o que fez, consequentemente não houve alternativa, qualquer possibilidade de escolha foi vedada ao indivíduo. A consequência imediata da aplicação do princípio do determinismo ao psiquismo seria, portanto, a negação da possibilidade da "liberdade" humana.

2) Correlativamente, ao estender o princípio do determinismo à atividade pensante, estariam comprometidas, não só a possibilidade da liberdade humana, mas também a possibilidade de "verdade". Pois equivaleria a dizer que, ao emitirmos enunciados tais como o do princípio de identidade $(\mathrm{A}=\mathrm{A})$, nós o fazemos graças a uma causa que nos impele, obriga a dizer isso, e de maneira nenhuma porque atribuímos um valor de verdade superior a este juízo. É como se o naturalista afirmasse que, quando pensamos que proposições tais como $\mathrm{A}=\mathrm{A}$ são verdadeiras, isto se deve à nossa constituição psico-fisiológica individual, ou à da espécie humana em geral, e não ao fato de serem realmente objetivas. De tal maneira que - seguindo ainda o raciocínio naturalista - caso fôssemos seres dotados de uma estrutura psico-orgânica distinta, poderíamos tranquilamente afirmar, por exemplo, que $\mathrm{A} \neq \mathrm{A}$ ! Ora, como não ver que, ao atrelar a verdade a uma causa psicofisiológica, termina-se por negar a própria possibilidade da verdade?

3) Além disso, o projeto de tornar inteligível o psiquismo segundo uma determinação natural implica na impossibilidade de responsabilizar o homem. A responsabilidade classicamente é definida como a possibilidade que tem o sujeito de responder por seus atos. Ora, só é possível responder por um ato quando se foi livre para realizá-lo. Só faz sentido atribuir responsabilidade a alguém quando o sujeito é capaz de, diante das infinitas possibilidades de ação que estão abertas a ele, escolher livremente uma em detrimento de outras. Se ele não tiver escolha, se for levado a agir de determinada maneira constrangido por uma causalidade exterior, não há como imputar-lhe responsabilidade. No direito, por exemplo, é uma questão importante saber se alguém pode ser julgado imputável: pois só faz sentido repreender alguém, mandando-lhe para a prisão ou para a forca, se julgamos que esta pessoa era livre para escolher seguir a lei, mas não o fez. Se o indivíduo em questão não teve escolha (por exemplo, foi submetido à pressão de um impulso natural), juridicamente ele é considerado inimputável. Ou seja, a condição necessária da responsabilidade é a liberdade, e a negação desta última acarreta por conseguinte a negação da "responsabilidade". Resumindo, postular uma explicação determinista do psiquismo acarreta uma tripla negação: da liberdade humana, da verdade e da responsabilidade.

Talvez poucos naturalistas ousariam reconhecer-se integralmente em tais teses, a maioria teria franca dificuldade em ratificá-las ao se depararem com colocações assim tão cruas. Contudo, as três consequências enumeradas decorrem logicamente dos projetos de naturalização do psíquico, por conseguinte quem aceita suas premissas deve assumir as consequências, se quiser sustentar uma posição coerente; recusar-se a subscrevê-las significa obrigatoriamente renunciar a fazer do homem objeto de ciência natural. 
Evidentemente, a tripla negativa sofreu enérgico repúdio por parte sobretudo dos teóricos que se filiavam à tradição racionalista. Segundo eles, o sujeito não era causado por nada, mas sim causa de si, portanto livre e capaz de escolher. Mas não se trata aqui de uma causa metafísica, ou seja, de um espírito capaz de causar efeitos no mundo físico, mas sem ser ele mesmo efeito de nada. O sujeito pode atuar, sim, como causa incausada, mas jamais relativamente ao mundo material este será em definitivo relegado à ciência física. Resta uma alternativa: ao sujeito encontra-se aberta a possibilidade de exercer sua liberdade ao atuar como agente moral. Esta solução, pensada por Kant (CHATELET, 1972), fornecerá a fonte de inspiração para diversas formulações posteriores, das quais destacamos a tese de W. Dilthey (1986[1883]) acerca da distinção entre o mundo natural e o mundo do sentido; bem como o pensamento de Husserl (ENGEL, 1996), defendendo a existência de um "segundo reino" que, autônomo e separado em relação ao "reino da natureza", seria composto pelas significações, pela lógica e pelas matemáticas. Inspirando-se nesses argumentos, Lacan (1998[1953]) procura situar o sujeito psicanalítico em outro registro que não o da objetividade, simultaneamente combatendo qualquer assimilação da psicanálise às ciências da natureza.

Segundo Lacan (1998[1946], p.153), enquanto a ordem física pode se exprimir sob a forma de relação entre uma função e uma variável, ou seja, sob forma determinista, o mesmo não acontece com a ordem própria ao psíquico. Ali, advém algo de não calculável, algo de não determinável antecipadamente: o sentido (MILLER, 1988). Este não é o efeito de uma causa material, ele surge graças a um ato livre do sujeito. Ou seja, no psiquismo haveria inicialmente, não "determinação", mas uma "indeterminação", uma lacuna que seria preenchida por um ato do sujeito, graças ao qual adviria o sentido. O sentido não se encontrando dado previamente, requereria portanto um ato livre de doação por parte do sujeito.

Seriam postulados então dois domínios coexistindo paralelamente - o da realidade física e o do sentido- exibindo características radicalmente distintas, merecendo portanto modos de investigação específicos: enquanto as ciências naturais tentariam tornar inteligíveis "fatos", as ciências da compreensão investigariam o que é da ordem do "sentido". Os dois domínios estudados permaneceriam heterogêneos e incomunicáveis, isto é, sem qualquer possibilidade de interferência mútua. Segundo esta tese, seria então inconcebível que o sentido tivesse o poder de alterar os fatos: a única maneira de modificar fatos seria intervindo nas sequências causais - ou seja, adicionando ou suprimindo outros fatos. Reciprocamente, não haveria a possibilidade de um fato determinar certo sentido, já que a emergência deste seria sempre função da liberdade do sujeito. Daí a famosa frase: "Tudo depende do sentido que se dá a isso" significar, não a negação da existência dos fatos, mas de seu poder de deflagrar no sujeito certa resposta.

A definição do sujeito como aquele que dá sentido ao que lhe acontece permitirá a Lacan escapar da tripla negativa:

1) O sujeito é livre - Neste ponto, cabe precisar em que sentido convém entender o conceito de liberdade. Pois seria legítimo indagar se, ao valorizarem o sujeito como um ser que doa sentido, não estariam os humanistas -Lacan aí 
compreendido - arriscando-se a cair numa espécie de absolutização da liberdade. Afinal de contas, não seria excessivo afirmar que essa doação de sentido se daria ex-nihilo, como se nada a precedesse no tempo? Esta objeção pecaria por desconhecer totalmente a posição humanista, já que, segundo eles, o homem é certamente um ser livre, mas também é sempre um ser-em-circunstância, um ser referido a certas condições que o precedem, situado em relação a certas coordenadas históricas. Lacan não afirma, portanto, que o sujeito não tenha relação com nada anterior a ele, apenas nega que tal relação possa ser concebida de forma determinista. "Se há, pode-se admitir, condições do sentido - pois trata-se de dar sentido a 'isso' que está aí - , isto não quer dizer que haveria causas do sentido. Há um hiato, aqui, entre a condição e a causa, já que a causa determina." (MILLER, 1988, p.79, grifo nosso).

Pois, enquanto no domínio da realidade física uma causa A provoca necessariamente como efeito $\mathrm{B}$, no registro do sentido uma condição A pode produzir $n$ efeitos distintos, ou seja, há indeterminação, sendo o efeito fruto de uma escolha livre. Por exemplo, um menino recebe um tapa (A) produzindo como "efeito" um choro (B) (LACAN, 2002[1955-1956], p. 15). Haveria aí uma relação de causa a efeito? Não, pois, segundo Lacan, podem ser variadas as reações do menino (B) à pancada (A): ele pode, em vez de chorar, revidar, achar que mereceu, dar a outra face, reclamar, interpretar como carinho, e assim indefinidamente. Se fossem causas, a resposta estaria determinada pelo tapa. Trata-se aqui antes de condições, não de causas: as condições são algo mais amplo, deixando margem a uma indeterminação, abrindo um hiato que convoca o sujeito a responder (MILLER, 1988).

2) O sujeito é capaz de verdade - Esta tese foi levada tão a sério por Lacan que ele ousou afirmar a possibilidade da verdade ali mesmo onde os mais empedernidos racionalistas acreditavam encontrar seu limite: a saber, no campo das psicopatologias. A partir daí, torna-se compreensível o teor da crítica dirigida a Pierre Janet, o qual, atribuindo a histeria a uma fraqueza congênita da síntese psíquica, acabava destituindo a fala histérica de qualquer verdade, tornando-a uma mera emissora de sons. Conforme demonstra Janet (apud LACAN, 1998[1953], p. 307):

Ela [a histérica] nada compreende da ciência e não imagina que possamos interessar-nos por isso [...] Se pensarmos na falta de controle que caracteriza seu pensamento, em vez de nos escandalizarmos com suas mentiras, que aliás são muito ingênuas, ficaremos surpresos, antes, de que ainda haja tantas que são sinceras.

Já Freud teria procedido de maneira inteiramente distinta, ao haver revelado ser o discurso histérico portador de um sentido cifrado, portanto de uma verdade que não se apresenta de maneira imediata.

Pois, se Freud tivesse sido capaz de assiná-las [as linhas supracitadas, escritas por Janet], como poderia ter ouvido, da maneira como ouviu, a verdade incluída nas historietas de suas primeiras doentes, ou decifrado um delírio obscuro como 
o de Schreber, a ponto de ampliá-lo proporcionalmente ao homem eternamente acorrentado a seus símbolos? (LACAN, 1998 [1953], p. 308, grifo nosso).

Outro alvo forte de crítica será a posição da psiquiatria segundo a qual o louco, homem cujo discurso parecia completamente destituído de qualquer racionalidade, estaria, portanto, excluído do campo da verdade. O louco constituiria uma exceção, já que seu psiquismo, ao contrário dos indivíduos normais, não seria capaz de obedecer às regras da racionalidade e da lógica, estando consequentemente submetido a uma legislação causal. A partir do momento em que se considera a fala do louco desprovida de sentido, incapaz de dizer algo verdadeiro, automaticamente retira-se sua liberdade e sua responsabilidade, não restando à psiquiatria outra alternativa senão situar a loucura como resultando de uma causalidade orgânica. É o que defende Henri Ey (1950[1946], p.20), psiquiatra pertencente à corrente organicista: "as doenças mentais são insultos e entraves à liberdade: elas não são causadas pela atividade livre, isto é, puramente psicogenéticas". Ou seja, se a gênese da atividade psíquica do indivíduo normal é atribuível ao seu próprio psiquismo ( $p$ sico- gênese), a mente louca o seria graças a uma causalidade orgânica (organo-gênese).

Não aceitando o triplo veto imposto pelo organicismo à loucura, em seu texto "Formulações sobre a causalidade psíquica" Lacan (1998[1946]) elegerá como interlocutor H. Ey como alvo preferencial de ataques. A nosso ver, a razão desta escolha recaiu sobre o fato de Ey ser, entre os organicistas, um dos adversários mais sofisticados e mais difíceis de combater, uma vez que defendia um tipo de determinismo "não-mecanicista" do mental pelo orgânico. Tal posição, denominada organo-dinamicismo, constituía um organicismo, enriquecido por elementos do dinamismo, do energetismo e do gestaltismo.

Neste debate acerca da gênese da loucura, Lacan defende que o discurso patológico, ao contrário do que pensa Ey, não é destituído de sentido, ele possui um sentido, apenas este sentido não pertence à ordem da compreensão. Portanto, a fala do louco pode ser situada inteiramente no campo da verdade. Lacan alega como argumentos que o sujeito interpreta os fenômenos que o assediam - alucinações, interpretações, intuições - como endereçados a ele, como possuindo uma significação, mesmo que tal significação não seja imediatamente legível:

esses fenômenos [...], não importa com que alheamento e estranheza sejam vividos por ele, todos o visam pessoalmente, eles o desdobram, respondem-lhe, fazemlhe eco e lêem nele, assim como ele os identifica, interroga, provoca e decifra. [...] toda a loucura é vivida no registro do sentido (LACAN, 1998[1946], p. 166).

Dessa forma, reinstala-se no coração da loucura a possibilidade de verdade _ "vocês verão que a verdade condiciona em sua essência o fenômeno da loucura (LACAN, 1998[1946], p. 154)._bem como a de liberdade _[a loucura 
exige] "o inapreensível consentimento da liberdade" (LACAN, 1998[1946], p. 188) - e da responsabilidade - [a loucura como] "insondável decisão do ser" (LACAN, 1998[1946], p. 179).

3) O sujeito é responsável- A estratégia de responsabilização do sujeito jamais será abandonada ao longo do ensino de Lacan, já que representa a condição que torna possível um tratamento analítico. Afinal de contas, se a causa do sofrimento devesse ser buscada num objeto exterior ao sujeito, o princípio de sua remoção deveria ser uma intervenção ela também objetiva. Dessa maneira, o trabalho analítico não visa:

[...] um objeto para-além da fala do sujeito, como alguns se empenham em nunca perder de vista. Se tivesse que ser essa a via da análise, sem dúvida alguma seria a outros meios que ela recorreria, ou então, esse seria o único exemplo de um método que proibisse a si mesmo os meios de atingir seu fim (LACAN, 1998[1953], p. 255).

Segundo o Lacan de "Função e campo...", se a fala efetivamente tem um poder curativo, é por ser agente de reestruturação do sentido. Inversamente, o padecimento psíquico ocorre quando algo não foi dito, isto é, não foi integrado ao sentido, permanecendo como um "capítulo censurado" de minha história. (LACAN, 1998[1953], p. 260) De qualquer maneira, tanto o reconhecimento num certo sentido, quanto a censura, recusa de aceitação numa certa ordem, são atos imputáveis apenas ao próprio paciente. Tanto num caso, quanto no outro, o sujeito é a causa. Portanto, um tratamento analítico somente pode deslanchar ao contar com a colaboração do sujeito.

\section{Parte II. Como a noÇão de Sentido afeta A ConcepÇão E a ConduÇão DO TRATAMENTO ANALÍTICO}

Freud já havia colocado em relevo, a ponto de considerá-la pilar fundamental da análise, a função dos acontecimentos passados na estruturação da vida psíquica. No entanto, a valorização lacaniana da história significará, mais que uma mera retomada deste antigo tema freudiano, um verdadeiro reexame do mesmo, à luz agora do conceito de sentido: o que pode ser a história, se o sujeito é um ser capaz de doar sentido? A partir daí, a história não poderia ser concebida como uma mera coleção de fatos passados. A função histórica residiria na possibilidade de dar sentido, isto é, de "pensar o que foi a partir do que deverá ser".

Para melhor esclarecer este ponto, é preciso entender que uma das características do sujeito é ser um "projeto", arremessando-se rumo ao futuro, antecipando como possível o que não é ainda. Ao colocar um futuro como devendo ser, o passado passa a ser visto como uma preparação do porvir. "Só fui assim para me transformar no que posso ser" (LACAN, 1998[1953], p. 252). Trata-se de uma perspectiva teleológica, em que o passado é pensado como uma etapa preparatória para a realização de uma finalidade futura. Por exemplo, se alguém pensa no comunismo como fim da história, a luta de classes passa a ser pensada 
como uma etapa a ser ultrapassada na direção daquela meta. Assim, o sentido permitiria "reordenar as contingências passadas dando-lhes o sentido das necessidades por vir" (LACAN, 1998[1953], p. 257).

Os fatos passados, considerados em si mesmos, não têm qualquer importância para o sujeito, sua relevância sendo sempre determinada a posteriori: o passado não é algo que "foi", mas que "terá sido" conforme qual finalidade penso dever se realizar. Temos aqui um regime do futuro anterior ("terá sido"), que torna o passado uma configuração sempre móvel, já que ordenada em função do modo pelo qual, no presente, concebo o futuro (ALBUQUERQUE, 1998, p. 51).

Se o sujeito é doação de sentido, cabe perguntar: de onde surge o sofrimento psíquico? A resposta de Lacan (1998[1953]) em "Função e campo ..." é que a lembrança traumática consiste em uma significação que não pôde ser integrada pela consciência porque entrou em contradição com o projeto no qual o sujeito se encontra engajado. Nesta chave, pode-se perfeitamente ler uma passagem famosa do caso Elizabeth von R., a paciente de Freud que, ao receber a notícia da morte da irmã, pensa ter finalmente encontrado caminho livre para conquistar o cunhado - ideia que se revela tão insuportável a ponto de acabar sendo objeto de recalcamento. Se este pensamento pôde constituir um trauma, é devido a sua incompatibilidade com os ideais ético-religiosos que norteavam a conduta da moça, ou seja, devido a sua não integração ao sentido que orientava sua existência. A fim de livrar-se do conflito que a presença daquele corpo estranho acarretaria, o sujeito o censura, o que traz como consequência o ressurgimento da lembrança sob forma sintomática. O sintoma torna-se, então, "o significante de um significado recalcado da consciência do sujeito" (LACAN, 1998 [1953], p. 282).

Note-se que jamais devemos considerar o trauma um fato bruto, que viria de fora impor um sofrimento ao sujeito. Os fatos em si mesmos são insignificantes, sua importância podendo ser determinada somente a partir de um ato de doação de sentido pelo sujeito. Um evento só nasce psiquicamente a partir do momento em que é "historicizado", ou seja, que sua significação é fixada por certo referencial de avaliação. A própria condição de seu armazenamento como lembrança é que tenha valor semântico, que tenha sido "vivido como" certo sentido (MILLER, 1988). Se os fatos desempenharam um papel, "já foi como fatos históricos, isto é, como reconhecidos num certo sentido ou censurados numa certa ordem" (LACAN, 1998[1953], p. 289). O acontecimento traumático sempre se engendra então numa "historicização primária" (LACAN, 1998[1953], p. 262). É graças à historicização primária que se "humaniza o acontecimento" (LACAN, 1998[1953], p. 289). Pode-se, então, afirmar que Lacan aqui pensa que o trauma, por ser sempre já historicizado, seria passível de uma total reabsorção no campo do sentido. É interessante notar o quanto essa posição está a léguas de distância da famosa tese adotada por Lacan posteriormente, segundo a qual o traumatismo seria justamente o que se mostra heterogêneo ao simbólico, permanecendo um resto inassimilável, um impasse que não conseguimos significar completamente. 
Caso o sujeito em análise se dispusesse a integrar o estigma traumático em um novo horizonte de compreensão, o poder da lembrança se dissiparia, sendo seu destino um total apagamento. Graças à análise, o sujeito concederia à lembrança recalcada um estatuto diferente, integrando-a no interior de um novo projeto. $\mathrm{O}$ tratamento favorece a "meditação do sujeito rumo ao sentido a ser decidido do acontecimento original" (LACAN, 1998[1953], p. 258). Este sentido inédito, a ser decidido pelo sujeito em análise, denomina-se historicização secundária.

Caso o sujeito se negue a perlaborar o trauma, o resultado será o recalcamento. Contudo, conforme ensina Freud, se o recalque tem êxito em impedir o acesso de determinada ideia à consciência, não consegue, entretanto, destruíla: esta permanecerá ativa no inconsciente, de onde enviará para a consciência representantes. A interpretação lacaniana desta descrição metapsicológica é de que, ao não poder se dizer por meio das palavras, o trauma - capítulo da minha história que censurei - deverá conhecer outros destinos, utilizando-se de outros meios de expressão, mas geralmente um suporte corporal ou imaginário: "O inconsciente é o capítulo de minha história que é marcado por um branco ou ocupado por uma mentira: é o capítulo censurado. Mas a verdade pode ser resgatada: na maioria das vezes, já está escrita em outro lugar" (LACAN, 1998[1953], p. 260) sintoma será esta verdade inscrita em outro lugar, sob a forma de um suporte corporal ou imaginário: "nele, a fala é expulsa do discurso concreto que ordena a consciência, mas encontra apoio, quer nas funções naturais do sujeito, [...] quer nas imagens que organizam, no limite do Unwelt e do Innenwelt, sua estruturação relacional" (LACAN, 1998 [1953], p. 282). Inversamente, a tarefa do tratamento analítico seria a de levantar a barreira do recalcamento, possibilitando ao recalcado abandonar seu suporte corporal ou imaginário e encontrar um suporte simbólico, a palavra.

Ao conceber o tratamento como a liberação do sentido dos sintomas, Lacan aproxima a psicanálise de uma hermenêutica. A hermenêutica é um empreendimento de decifração de signos, cujo sentido profundo não se revela imediatamente (GRONDIN, 1999). A proximidade entre as duas seria tão grande, a ponto de Lacan ver pontos de contato entre a psicanálise e a exegese (LACAN, 1998[1953], p. 282) - que, como explica Jean Grondin, é uma hermenêutica de textos bíblicos.

Por meio da palavra, o pensamento outrora considerado traumático poderia a posteriori ser reintegrado no interior de um novo sentido, resultando numa historicização secundária. A meta da psicanálise seria a obtenção de uma "palavra plena", que teria a propriedade de abolir o recalcamento, superando a cisão significado/significante. Desse modo, seria conseguido o perdão da palavra (MILLER, 2005, p. 44). 


\title{
OBSERVAÇões FINAIS
}

Conforme demonstrado, a noção de sentido foi de extrema importância no combate travado contra as posições que consideravam a psicanálise uma ciência natural. Dessa forma, contribuiu para estabelecer o domínio próprio de tratamento dos problemas analíticos: pois não é no registro da objetividade que se pode buscar a causa do sofrimento, mas sim na relação do sujeito com sua fala.

No entanto, pode-se dizer que a noção de sentido foi mais importante pelo que rejeitou como falso do que pelo que afirmou como verdadeiro. Pois os desenvolvimentos posteriores da obra de Lacan pouco irão conservar da proposta de "Função e Campo...": enquanto ali, o propósito da psicanálise seria a obtenção de uma fala plena, onde o desejo que se revelou traumático no interior de certo sentido pudesse ser reintegrado num sentido novo, todo o ensino posterior de Lacan se esforçará por mostrar que não há fala plena, não há a menor possibilidade de o sujeito entrar em acordo com seu desejo, a conciliação entre o significante e o significado será estruturalmente impossível. A partir daí, o desejo não será mais o que pode ser dito na palavra plena, mas sim a impossibilidade de tal palavra.

\section{Notas}

\begin{abstract}
1 "O historiador da ciência deve tomar as idéias como se fossem fatos. O epistemólogo deve tomar os fatos como se fossem idéias, inserindo-os num sistema de pensamento. Um fato mal-interpretado por uma época permanece, para o historiador, um fato. Para o epistemólogo, é um obstáculo, um contra-pensamento" (BACHELARD, 1996, p. 22).
\end{abstract}

\section{REFERÊNCIAS}

AGUIAR, A. A. A psiquiatria no divã: entre as ciências da vida e a medicalização da existência. Rio de Janeiro: Relume Dumará, 2004.

ALBUQUERQUE, A. C. A causa da psicanálise. 1998. Dissertação (Mestrado)-Universidade Federal do Rio de Janeiro, Rio de Janeiro, 1998.

BACHELARD, G. A formação do espírito cientifico. Rio de Janeiro: Contraponto, 1996.

BLANCHÉ, R. L'induction scientifique et les lois naturelles. Paris: P.U.F., 1975.

CHATELET, F. Logos e praxis. Rio de Janeiro: Paz e Terra, 1972.

DILTHEY, W. Introducción a las ciencias del espíritu (1883). Madrid: Alianza, 1986.

ENGEL, P. Philosophie et psychologie. Paris: Gallimard, 1996. 
EY, H. Les limites de la psychiatrie: le problème de la psychogenése (1946). In: BONNAFÉ, L. et al (Ed.). Le probléme de la psychogenése des névroses et des psychoses. Paris: Desclée de Brouwer \& cie, 1950. p. 9-20.

GRONDIN, J. Hermenêutica: introdução à hermenêutica filosófica. São Leopoldo: Unisinos, 1999.

LACAN, J. Formulações sobre a causalidade psíquica (1946). In:

Escritos. Rio de Janeiro: J. Zahar, 1998. p. 152-194.

. Função e campo da fala e da linguagem (1953). In: . Escritos. Rio de Janeiro: J. Zahar, 1998. p. 238-324. $\overline{\text { Livro } 3}$.

O seminário: as psicoses (1955-1956). Rio de Janeiro: J. Zahar, 2002.

MILLER, J. A. Cause et consentement. Seminário Inédito, 1988. . Silet. Rio de Janeiro: J. Zahar, 2005.

MONZANI, L. R.. Freud: o movimento de um pensamento. Campinas: Unicamp, 1989.

RUSSELL, B. Misticismo e lógica. São Paulo: Companhia Editora Nacional, 1957.

ZIZEK, S. Suversions du sujet: psychanalyse, philosophie, politique. Rennes: Presses Universitaires de Rennes, 1999

Recebido em:

Aceito em: 